\title{
Derangement of cardiac energy metabolism is acutely exacerbated during exercise in hypertrophic cardiomyopathy, independent of hypertrophy or late gadolinium burden
}

\author{
Sairia Dass ${ }^{1 *}$, Lowri E Cochlin², Joseph Suttie ${ }^{1}$, Cameron Holloway ${ }^{1}$, Christopher T Rodgers $^{1}$, Damian Tyler ${ }^{2}$, \\ Theodoros Karamitsos ${ }^{1}$, Kieran Clarke², Hugh Watkins ${ }^{1}$, Stefan Neubauer ${ }^{1}$
}

From 15th Annual SCMR Scientific Sessions

Orlando, FL, USA. 2-5 February 2012

\section{Summary}

This work demonstrates that cardiac energetcics is further impaired during exercise in hypertrophic cardiomyopathy. This may be a possible reason for exercise related death in HCM.

\section{Background}

In hypertrophic cardiomyopathy (HCM), sarcomere mutations increase the energy cost of contraction. Impaired resting cardiac energetics as measured by phosphocreatine/adenosine triphosphate (PCr/ATP) using 31Phosphorus MR Spectroscopy(31P MRS) has been documented in animal models and patients.

We hypothesize that: 1.Cardiac energetics are further impaired acutely during exercise in HCM, which does not occur in normals or athletes (physiological hypertrophy); 2. This impairment is not related to the degree of hypertrophy or late gadolinium enhancement (LGE) burden.

\section{Methods}

Cardiac 31P MRS (3T) was performed in $35 \mathrm{HCM}$ patients, 12 athletes and 20 normal controls (all ageand gender-matched) at rest and during 8 minutes of prone leg exercise with $2.5 \mathrm{~kg}$ weights attached to both legs. Cine and LGE images were also acquired.

'Deprtment of Cardiovascular Medicine, University of Oxford, Oxford, UK Full list of author information is available at the end of the article

\section{Results}

Increases in rate pressure product with exercise were similar: normal $72 \pm 44 \%$; HCM $73 \pm 38 \%$; Athlete $75 \pm 47 \%$.

There was no difference in resting PCr/ATP between normals $(2.14 \pm 0.36)$ and athletes $(2.04 \pm 0.32, \mathrm{P}=0.36)$. Resting PCr/ATP was significantly reduced in HCM, $(1.71 \pm 0.35, \mathrm{P}<0.01$ compared to normal and athletes, figure 1).

During exercise, there was a further reduction in $\mathrm{PCr} /$ ATP in HCM $(1.56 \pm 0.31, \mathrm{P}<0.05)$, but no significant change in normals $(2.13 \pm 0.34, \mathrm{P}=0.98)$, and athletes $(2.09 \pm 0.50, \mathrm{P}=0.63$, figure 1$)$. The change of $\mathrm{PCr} / \mathrm{ATP}$ during exercise in HCM $(-0.14 \pm 0.34)$ was significantly different $(\mathrm{P}<0.05)$ from the change in normals $(+0.05$ \pm 0.27 ).

LV mass index was higher in HCM $(90 \pm 14 \mathrm{~g} / \mathrm{m} 2)$ and athletes $(92 \pm 19 \mathrm{~g} / \mathrm{m} 2)$ compared to normal $(65 \pm 10 \mathrm{~g} / \mathrm{m} 2)$ $\mathrm{P}>0.05$. There was no correlation between cardiac mass index and rest $\mathrm{PCr} / \mathrm{ATP}$ ratios (HCM: $\mathrm{R}=0.01, \mathrm{P}=\mathrm{NS}$; athletes: $\mathrm{R}=0.22 \mathrm{P}=\mathrm{NS}$ ) or change in $\mathrm{PCr} / \mathrm{ATP}$ with exercise.

In HCM, average wall thickness at voxel placement for $\mathrm{PCr} / \mathrm{ATP}$ was $18 \pm 6 \mathrm{~mm}$ (range $7.8-28.8 \mathrm{~mm}$ ). This did not correlate with resting $\mathrm{PCr} / \mathrm{ATP}$ or change in energetics with exercise. Wall thicknesses were normal in the athlete group, $9 \pm 2 \mathrm{~mm}$.

Normals and athletes had no LGE. In HCM, the average LGE $>2$ SD in the mid ventricular septum was 24 $\pm 15 \%$. LGE correlated weakly with resting PCr/ATP ratio, $(\mathrm{R}=-0.35, \mathrm{P}=0.04)$, and did not correlate with absolute exercise or change in PCr/ATP with exercise.

( 2012 Dass et al; licensee BioMed Central Ltd. This is an open access article distributed under the terms of the Creative Commons Attribution License (http://creativecommons.org/licenses/by/2.0), which permits unrestricted use, distribution, and reproduction in any medium, provided the original work is properly cited. 


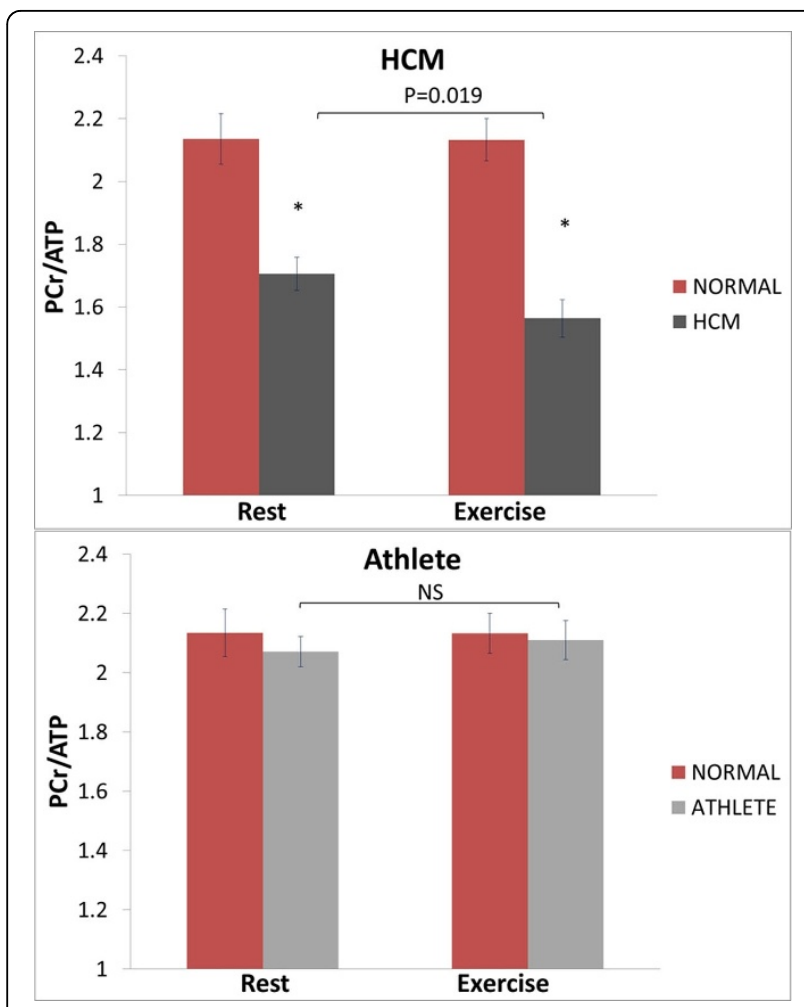

Figure 1 The effect of exercise on PCr/ATP in normal controls, $\mathrm{HCM}$, and Athletes, showing a reduction in the HCM group, but no change in athletes or normal. ${ }^{*} p<0.05$ vs normal.

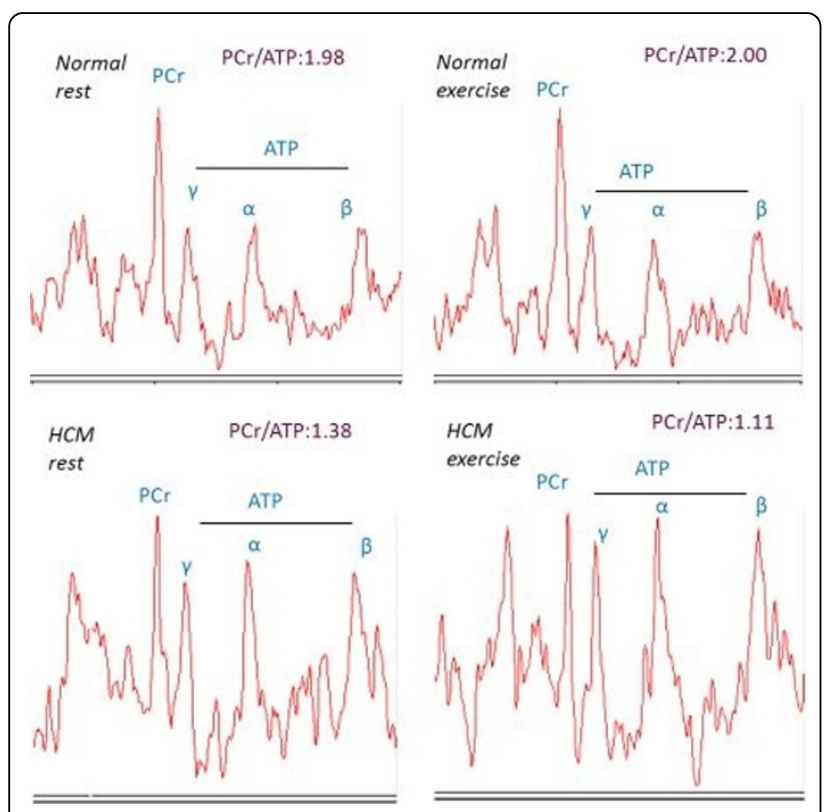

Figure 2 Examples of rest and exercise energetics in normal and HCM.

\section{Conclusions}

During exercise, the pre-existing energetic deficit in HCM is further exacerbated and is not influenced by the degree of hypertrophy or scar burden. Acute derangement of energy-dependent ion homeostasis, triggering $\mathrm{Ca}++$ overload and ventricular arrhythmias, may be a possible explanation for the high incidence of exercise-related death in HCM. Treatments that optimize energetics may be protective.

\section{Funding}

This research was funded by the British heart foundation.

\section{Author details}

${ }^{1}$ Deprtment of Cardiovascular Medicine, University of Oxford, Oxford, UK. 2Deprtment of Physiology, Anatomy and Genetics, University of Oxford, Oxford, UK.

Published: 1 February 2012

doi:10.1186/1532-429X-14-S1-O75

Cite this article as: Dass et al:: Derangement of cardiac energy metabolism is acutely exacerbated during exercise in hypertrophic cardiomyopathy, independent of hypertrophy or late gadolinium burden. Journal of Cardiovascular Magnetic Resonance 2012 14(Suppl 1): 075.
Submit your next manuscript to BioMed Central and take full advantage of:

- Convenient online submission

- Thorough peer review

- No space constraints or color figure charges

- Immediate publication on acceptance

- Inclusion in PubMed, CAS, Scopus and Google Scholar

- Research which is freely available for redistribution 